tions (defined as more than 200 CGG repeats in the first exon of the fragile $X$ mental retardation gene), in which the abnormal methylation associated with large expansions shuts off the expression of the target gene.

The next few months should witness a series of studies that will establish the epidemiological importance of SCA8 as a cause of spinocerebellar ataxia in familial and sporadic cases in different populations. The loci previously characterized account for 60 to $80 \%$ of SCA families (and for a much smaller proportion of sporadic cases), and three additional SCA loci mapped in single families remain to be cloned (SCA4, 5 and 10)(refs. 9,10). Such studies will also establish on firmer grounds the transmission properties of SCA8 and the relations between repeat size and clinical features, such as penetrance, severity and age at onset. This will be essential for applications to diagnosis and genetic counseling.

A much more difficult problem will be determining why the repeat is pathogenic. If, as with fragile $X$ or progressive myoclonus epilepsy, the SCA8 expansion causes a loss of function of a single gene, one would expect to find conventional mutations in that gene causing a similar clinical phenotype. The possibility of a toxic protein mechanism as in other SCAs is excluded because the repeat is untranslated. Koob and colleagues suggest that the SCA8 expansion affects a low abundance antisense transcript that could in turn regulate expression of an overlapping protein coding gene. However, a detailed transcript map of the region is lacking, and it is possible that another nearby gene is affected by the mutation. Finally, we must remember the sobering example presented by DM: 7 years after the characterization of the mutation for this disease, its exact mode of action is still not fully understood.

1. Genetics Instabilities and Hereditary Neurological Diseases. (eds. Wells, R.D. \& Warren, S.T.) (Academic, San Diego, 1998).

2. Lunkes, A. \& Mandel, J-L. Polyglutamines, nuclear inclusions and neurodegeneration. Nature Med. 3, 1201-1202 (1997).

3. Kim, T-W. \& Tanzi, R.E. Neuronal Intranuclear inclusions in polyglutamine diseases: Nuclear
Weapons or Nuclear Fallout? N euron 21, 657-659 (1998).

4. David, G. et al. Molecular and clinical correlations in autosomal dominant cerebellar ataxia with progressive macular dystrophy (SCA7). Hum. Mol. Genet. 7, 165-170 (1998)

5. Jodice, C. et al. Episodic ataxia type 2 (EA2) and spinocerebellar ataxia type 6 (SCA6) due to CAG repeat expansion in the CACNA1A gene on chromosome 19p. Hum. Mol. Genet. 6, 1973-1978 (1997).

6. Koob, M.D. et al. An untranslated CTG expansion causes a novel form of spinocerebellar ataxia (SCA8). Nature Genet. 21, 379-384 (1999).

7. Schalling, M. et al. Direct detection of novel expanded trinucleotide repeats in the human genome. Nature. Genet. 4, 135-139 (1993).

8. Lindblad, K. et al. Two commonly expanded CAG/CTG repeat loci: involvement in affective disorders? M ol. Psychiatry 3, 405-410 (1998).

9. Takano, $\mathrm{H}$. et al. Close Associations between prevalences of dominantly inherited spinocerebellar ataxias with CAG-repeat expansions and frequencies of large normal CAG alleles in Japanese and Caucasian populations. Am. J. Hum. Genet. 63, 1060-1066 (1998).

10. Moseley, M.L. et al. Incidence of dominant spinocerebellar and Friedreich triplet repeats among 361 ataxia families. Neurology 51, 1666-1671 (1998).

Institut de Genetique et de Biologie M oleculaire et Cellulaire

CNRS/INSERM/Universite Louis Pasteur

BP163, 67404 IIIkirch Cedex, CU Strasbourg France

\title{
The 1918 'Spanish' flu: pearls from swine?
}

\begin{abstract}
An unexpected marriage between modern biological technology and past records suggests that the influenza $\mathrm{A}$ (H1N1) viruses are a long-established family from China, not Spain.
\end{abstract}

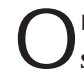
NE OF THE LONG-STANDING, controversial issues in virology is the nature and origin of the virus that caused the so-called 'Spanish' flu pandemic of 1918, an outbreak that claimed the lives of as many as 1 in 100 of the world's population of the time. With the thought still fresh in mind that if it were not for the slaughtering of 1.5 million chickens and other poultry in the 1997 Hong Kong H5N 1 'bird flu' incident, we might have have seen another pandemic, any retrospective insight into events surrounding the 1918 outbreak could prove useful in future prevention and control strategies. Until now, progress towards a better understanding of the 1918 event has been bedevilled by the unavailability of viruses from the pandemic. Now, Reid et al. ${ }^{1}$ describe formalin-fixed, paraffin-embedded archival lung tissue from two US soldiers, and formalin-fixed, frozen lung tissue from an Inuit woman buried in permafrost in Alaska, all of whom succumbed to the 1918 pandemic.

It is known that substitution of the HA

\section{KENNEDY F. SHORTRIDGE}

gene of a prevailing human influenza $A$ virus through reassortment is the basic requirement for the genesis of a new pandemic virus. Reid and colleagues have determined the entire HA sequence

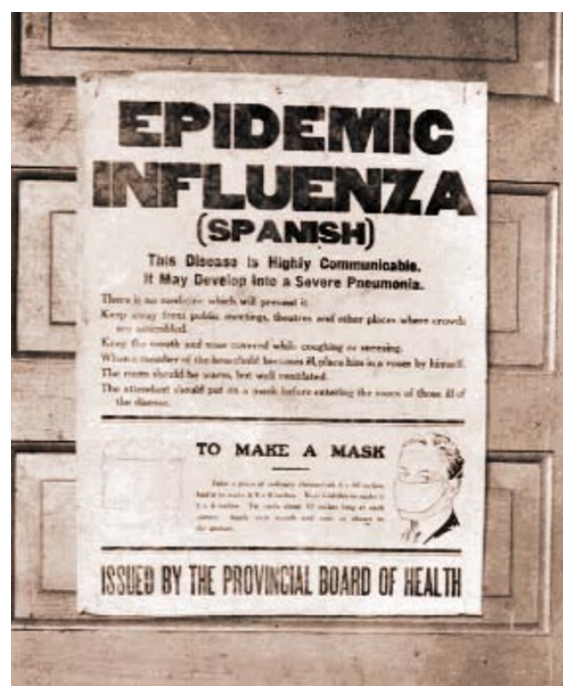

of 1701 nucleotides in 22 overlapping fragments of one archival sample and the HAl domain of the HA gene of the other two, and found a high degree of conservation. Phylogenetic analyses of the sequence indicate that it is mammalian and is located at the root of human and swine clades. However, it seems to be more closely related to avian than any other known mammalian $\mathrm{HA}$ sequence, and it may have been introduced into humans around 1915.

Assuming that the sequence of the $\mathrm{HA}$ gene that Reid and colleagues presented faithfully represents the 1918 virus (and it had not been passaged in the laboratory) and that the gene had been undergoing rapid evolution in the way newly introduced $\mathrm{H} 2, \mathrm{H} 3$ and $\mathrm{H} 5 \mathrm{HA}$ avian genes have don $\mathrm{e}^{2,3}$, there is in fact every possibility that the virus was introduced into the human host well before 1915 and had an avian ancestry. This suggests that the 1918 virus had been 'smoldering' in, or adapting to, the human host, and offers some support to the earlier suggestion that the human and swine 
lineages were derived from a common avian-like ancestor around 1905 (ref. 4).

But can this genetic data be reconciled with epidemiological observations of influenza in southern China before and after 1900? In the first phase of the 1918 pandemic in Canton (now called Guangzhou) in Guangdong Province adjacent to Hong Kong, most cases at the June outset were in people 11-20 years of age, with a male preponderance, whereas in October of that year most were between 11 and 15 years of age $^{5}$. Mortality was relatively low. This is in contrast to the situation in Europe and the US in 1918, in which all ages were apparently affected, with most deaths occurring in young adults and particularly $15-$ to 34-year-olds ${ }^{6,7}$, suggesting that people in these regions had not experienced as extensive previous exposure to $\mathrm{H} 1$-like viruses as those in southern China seem to have experienced.

Thus, in Canton at least, those born between 1898 and 1907 would have had little or no antibody to the $\mathrm{H} 1$ subtype, implying that an H1-like virus may have been circulating before 1898 and from 1907 to 1918. If this is so, and if the seroarchaeological data on the occurrence of $\mathrm{H} 2$ - and $\mathrm{H} 3$-like subtypes in Europeans and Americans from 1889 to 1917 (reviewed in ref. 6) are applicable to the southern Chinese of the time, it seems likely that not only did an $\mathrm{H}$ 1-like virus circulate in southern China from 1907 to 1917 but also it would have cocirculated with an $\mathrm{H} 3$-like virus perhaps in the same way that $\mathrm{H} 1$ and $\mathrm{H} 3$ subtype viruses have been co-circulating in the third quarter of this century.

Indeed, it was in Canton in September and October 1888 that "the first recorded appearance of the modern influenza epidemic" was made ${ }^{8}$, an epidemic that apparently gave rise to the pandemic of 1889 caused by an H2-like virus that, as might be inferred from the above, would have co-circulated with the already-established H1-like subtype until 1898, when both subtypes were presumably eclipsed by the H3-like virus. These data indicate that over the last 110 years or so, an $\mathrm{H} 1$-like virus was present at least in southern China for about 70 of those years, during which time it has recycled on four occasions, once with an $\mathrm{H} 2$-like virus and three times with $\mathrm{H} 3$ or $\mathrm{H} 3$-like viruses.

How long before 1888 might the $\mathrm{H} 1$ like virus have occurred in humans? Linear regression analysis of the nucleoprotein (NP) genes of a range of avian, swine and human $\mathrm{H} 1 \mathrm{~N} 1$ viruses extrapolate a common ancestor of current human influenza viruses to 1837 (ref. 9). This raises the possi bility that an $\mathrm{HI}$ like virus may have existed in humans, at least in southern China, for some 50 years before the earliest epidemiological evidence of its presence there (in 1888).

So where does this leave the idea that the 1918 pandemic had its origin(s) in Europe or the USA in late winter/early spring of 1918? I believe that southern China was the source of the virus, in keeping with the hypothesis that the region is a hypothetical influenza epicentre for the emergence of pandemic influenza viruses ${ }^{10}$, and it spread with the economy-driven movement of people out of Guangdong Province. The influenza viruses of modern times ( $\mathrm{H} 3 \mathrm{~N} 2$ and HIN1) in Hong Kong SAR and Guangdong Province mostly occur yearround sometimes with a minor peak in February and March and a single or major one in the summer in June to September ${ }^{11}$, and there is no reason to suppose that it would have been different in the early 1900s. In her documentary on the 1914-18 World War, MacDonald noted that many of the trenches were built by Chinese laborers who had been clustered around camps in Montreiul, France ${ }^{12}$. From her text, it is clear that those labourers were speaking the Cantonese dialect of Guangdong Province and it is plausible that they took with them to Europe and the USA the 'smoldering' or adapting human H1N1-like virus.

Reid et al. plan to examine other genes from the 1918 virus, and it remains to be seen what ancestral genetic images it will provide towards understanding the 1918 'Spanish' flu virus. If these data strengthen the idea that the virus originated in southern China, perhaps the term 'Spanish' flu might be quietly dropped.

\section{Acknowledgment}

I thank K. MacPherson, (Department of History, The University of Hong Kong) for historical advice.

1. Reid, A.H., Fanning, T.G., Hultin, J.V. \& Taubenberger, J.K. Origin and evolution of the 1918 "Spanish" influenza virus hemagglutinin gene. Proc. Natl. Acad. Sci. USA 96, 1651-1656 (1999).

2. Webster, R.G., Bean, W.J., Gorman, O.T., Chambers, T.M. \& Kawaoka, Y. Evolution and ecology of influenza A viruses. Microbiol. Rev. 56, 152-179 (1992)

3. Claas, E.C.J. et al. Human influenza A (H5N1) virus related to a highly pathogenic avian influenza virus. Lancet 351, 472-477 (1998).

4. Kanegae, Y., Sugita, S., Shortridge, K.F., Yoshioka, Y. \& Nerome, K. Origin and evolutionary pathways of the $\mathrm{H} 1$ hemagglutinin gene of avian, swine and human influenza viruses: co-circulation of two distinct lineages of swine virus. Arch. Virol. 134, 17-28 (1994).

5. Cadbury, W.W. The 1918 pandemic of influenza in Canton. China Med. J. XXXIV, 1-17 (1920).

6. Noble, G.R. in Basic and Applied Influenza Research. (ed. Beare A.S.) 11-50 (CRC, Boca Raton, 1982).

7. Taubenberger, J.K., Reid, A.H., Krafft, A.E., Bijwaard, K.E. \& Fanning, T.G. Initial genetic characterization of the 1918 'Spanish' influenza virus. Science 275, 1793-1796 (1997).

8. Cantlie, J. The first recorded appearance of the modern influenza epidemic. Br. Med. J. 491 (29 Aug. 1891).

9. Gammelin, M. et al. Phylogenetic analysis of nucleoprotein suggests that human influenza $A$ viruses emerged from a $19^{\text {th }}$-century avian ancestor. Mol. Biol. Evol. 7, 194-200 (1990).

10. Shortridge, K.F. \& Stuart-Harris, C.H. A pandemic influenza epicentre? Lancet ii, 812-813 (1982).

11. Reicheldelfer, P. et al. in Proceedings of the First Asia-Pacific Congress of Medical Virology. (eds. Chan, Y.C., Doraisingham, S. \& Lind, A.E.) 412-444 (World Scientific, Singapore, 1989).

12. MacDonald, L. Somme. Macmillan Publishers Limited, London p. 189-193 (1984).

Department of Microbiology

The University of Hong Kong

University Pathology Building

Queen Mary Hospital

Hong Kong SAR

China

Email: microgen@hkucc.hku.hk 